\title{
A global view of regulatory ecosystem services: existed knowledge, trends, and research gaps
}

\author{
Wondimagegn Mengist ${ }^{1,2^{*}}$, Teshome Soromessa ${ }^{2}$ and Gudina Legese Feyisa ${ }^{2}$
}

\begin{abstract}
Ecosystem services (ES) are growing fields of research. It helps to provide an inherent way to understand the synergy and trade-offs between human beings and their natural environment. Regulatory ecosystem services (RES) are significantly important to maintaining the world in which people can live, and control the negative effects of flood, disasters, and diseases. It can also provide regulatory services like ecosystem protection, human safety, and the provision of other ES. However, emerging ES decision-making agendas focus on ES that is tangible and has a direct link with human well-being. Thus, the attention given to RES is low due to its less tangible benefits and complexity to measure the benefits. Disregarding and lack of attention from policymakers and scientific community may lead to unintended risks to human well-being and significant influences on the provision of other ES. This study describes the research trends on RES, knowledge generated, and the major limitation. We concluded that though there is an exponential growth of scientific publications on ES, no adequate studies were found on RES. Also, the existed studies varied in their size and types of RES indicators covered, habitats/ecosystems, and geographic extent addressed. There was also a lack of connecting knowledge generated on the benefits of RES with the national policy of natural resource management, inconsistency of ES classification, and methodological diversity. Therefore, scientific communities are promoted to link RES studies with human health. Besides, the researcher should give priority for the least studied ecosystems and its services, developing robust methodology, and proposing management options to enhance the regulatory services of ecosystems.
\end{abstract}

Keywords: Ecosystem, Ecosystem service indicators, Less tangible benefits, Regulatory ecosystem services, Research trend, Undervalued services

\section{Introduction}

Ecosystem services (ES) are all the benefits which human can derive from the natural ecosystems for their physical, social, and economic well-being (Costanza et al. 1997; Daily 1997; MA 2005). Currently, the term ES is popular in contemporary scientific research and policy agenda (Braat and de Groot 2012; Fisher et al. 2009; Seppelt et al. 2011). This is because ES is highly valuable (Costanza et al. 1997) and beneficial to families,

\footnotetext{
* Correspondence: wondime2007@gmail.com

'Department of Natural Resource Management, Debre Berhan University, Debre Berhan, Ethiopia

${ }^{2}$ Center for Environmental Science, Addis Ababa University, Addis Ababa, Ethiopia
}

communities, and economies (Boyd and Banzhaf 2007) and helps to maintain the conditions of life on earth (Deal et al. 2012). Healthy functioning ecosystems have wide-ranging importance for human health by providing benefits like food, building materials, medicines, climate et al. 2012). lennium Ecosystem Assessment (MA 2005), The Economics of Ecosystems and Biodiversity, and The 
Common International Classification of Ecosystem Services (CICES) in 2010 (Haines-Young and Potschin 2011). Therefore, we prefer to use MA framework to structure our study analysis, because the framework is flexible and the most commonly used approach to evaluate ES in this study and others (e.g., Liquete et al. 2013; Mengist et al. 2019a; Talbot et al. 2018; Weitzman 2019). Based on the ES framework developed by MA in 2005, the variety of ES benefits to humans can be grouped into four classes: provisioning, regulating, cultural, and supporting services. Regulating ecosystem services (RES) are defined as "the benefits obtained from the regulation of ecosystem processes" (MA 2005). It comprises the various ways whereby the ecosystems regulate the natural environments. It helps to reduce the impacts and effects emanated from both natural and anthropogenic activities that cause risk to human health and ecosystem quality. RES, therefore, protect the natural environment using mechanisms like water purification and waste treatment, air quality maintenance, soil erosion control, flood protection, climate regulation, pest and disease regulation, pollination, and regulation of frequency and intensity of natural hazards' flow (Kandziora et al. 2013; MA 2005; Smith et al. 2013; Sutherland et al. 2018; Villamagna et al. 2013). Further, RES has a significant effect on the provisioning capacity of other ES (Boyd and Banzhaf 2007).

RES is grouped either in the final ES like climate regulation and natural hazard or in a significant leading to final ES such as water quantity and purification. Some other is primary or intermediate ES which includes pollination, disease, and pest regulation (Watson et al. 2011). Regulation services of natural hazards, for instance, flood regulation, are determined by the hydrological system (Stürck et al. 2014). Climate regulation is a final ES and includes absorbing greenhouse gases, enhancing evapotranspiration for rainfall occurrence, and controlling a surface albedo. This can extend from local to global scale regulatory services and has significant impacts on human well-being (Smith et al. 2013). Disease and pest regulation is an intermediate ES, and pollination is a primary or intermediate ES that has direct impacts on human well-being. It has large impacts by affecting the provisioning services like crops, plants, and livestock which are the main sources of food for humans (Watson et al. 2011).

Despite those benefits, RES is often less acknowledged and undervalued by people due to their less tangible benefits (Kandziora et al. 2013; Sutherland et al. 2018). It has difficulties measuring its contribution to human safety because RES provides indirect benefits to human well-being through maintaining the quality of the environment in a real sense which is critical services to the society. These caused RES to be overlooked in decision- making processes because more attention is given to ES that has more evident links with human well-being (Sutherland et al. 2018; Villamagna et al. 2013). Besides, RES is "process-driven," and data required to assess and evaluate the services at large scale were unavailable and become a bottleneck to mainstreaming into the policymaking agenda (Villamagna et al. 2013). There were also weak efforts to adequately connect regulating services with policymaking and ES assessment frameworks (Sutherland et al. 2018).

As a result of those challenges, RES becomes impeded from sufficiently considered in environmental decisionmaking processes. Thus, according to Sutherland et al. (2018), the ES management approach that ignores RES may bring "management trade-offs" that cause unsuitable environment for human health and favoring provisioning ES over RES that in turns induced pressure on the ecosystems. These also result in the undervaluing of ES and fail to fully understand the entire environmental and economic trade-offs (Keeler et al. 2012).

There were various review works on assessing and evaluating the state of the art of the ES. Just to list some of them: on ecosystem services in general (Seppelt et al. 2011), on trends of ES research (McDonough et al. 2017), on regulating ecosystem services (Sutherland et al. 2018), mapping ES value (Burkhard et al. 2012; Martínez-Harms and Balvanera 2012), the role of agriculture in ES (Tancoigne et al. 2014), economic valuation (Laurans et al. 2013), ecosystem services in landscapes (Englund et al. 2017), cultural ES (Milcu et al. 2013), ES integration with conservation (Egoh et al. 2007), with limited geographical areas, i.e., in Latin America (Balvanera et al. 2012), and Africa (Wangai et al. 2016), a meta-analysis of some key terrestrial regulatory ES (Viglizzo et al. 2016), and trends of forest ES (Mengist and Soromessa 2019). However, neither of the above studies so far addresses a detailed bibliographic review, spatial distribution, trends of indicator services and ecosystems, and gap on RES studies. Thus, we decided that it is important to provide information on the overall trends of RES research on a global scale. Also, the study can help researchers to identify the least and the most addressed indicators and its ecosystems, the types of challenges that the researchers were encountering, and the gaps that needed further research works.

Since ES provides a variety of benefits to human wellbeing, having a scientific output on ES can help to motivate policymakers to work towards reversing ecosystems from further degradation. Although human wellbeing is the core issue in ES, the existence of rapid population growth, economic growth, change in human consumption patterns, and climate change adversely affects the ES services. Accordingly, ES assessment is important to broaden the knowledge on ES, to raise the 
awareness level, and to be an agenda from global to the local level (Alamgir et al. 2014; Fagerholm et al. 2016). This study, therefore, formulated specific research questions. These were as follows: (1) What is state-of-the-art in RES? (2) Which RES indicator(s) had the highest and the least number of studies? (3) What are the current challenges impairing RES studies? and (4) What are the lessons learned and the way forward for ecosystem studies related to regulatory services?

The aim of the article is to provide an overall picture of trends of RES studies, give a comprehensive evaluation of the approaches used for ES assessment, map the conducted studies, and identify the gaps to be filled by future research works. Therefore, the work helps to define the status quo and deepen the trend analysis using related research papers. To that aim, the review addressed the following specific objectives:

- To analyze the state of the research trends on RES and the coverage of that published knowledge

- To identify the most and the least studied ecosystems and their regulatory ES indicators

- To analyze and highlight the main research gaps and pinpoint the way forward

\section{Methodology}

\section{Data sources}

The approach followed the literature search protocol of the Preferred Reporting Items for Systematic Reviews and Meta-Analyses (Moher et al. 2010). The review cannot be an exhaustive search of the literature, though it covers the largest parts of the related literature on the topic. The study covers limited databases such as Scopus, ScienceDirect, and Google Scholar. To guarantee the accuracy, this work was based on analytical processes from the framework of search (related articles from the identified databases), appraisal (include articles that include RES or regulating services on their title), synthesis (download and read the articles to include publications that cover at least one RES indicator), and analysis (extracting useful data from the included articles) (SALSA), which was applied by most reviews (Grant and Booth 2009; Malinauskaite et al. 2019; Mengist et al. 2019a; Perevochtchikova et al. 2019). The aim was to reduce the risk related to publication bias and to increase the scientific validity of the review work (Mengist et al. 2019b).

Before the actual systematic review search, a pilot literature search was done to refine the searching keywords to cover the targeted ES (Howe et al. 2014). The articles were peer-reviewed journals from the three data sources, and searches were finalized in April of 2019.

\section{Literature searching terms}

The following syntax was used: TITLE-ABS-KEY ("climate regulation" OR "air quality" OR "water regulation" OR "erosion regulation" OR "pest regulation" OR "pollination") AND TITLE ("regulating ecosystem service" OR "regulating service" OR "regulatory ecosystem services" OR "regulatory services"). As shown in Table 1, the search terms had run in separate or with limited combinations that considered the requirements, or limitations, of the database used.

\section{Article selection criteria}

Article selection followed sequential assessment steps. First, document abstracts were scanned to ensure the papers broadly addressed the following selection criteria, and if the papers did not meet the criteria, the papers were excluded. The literature from the databases was searched based on the following fixed set of inclusion criteria:

(i) The literature should address at least one service from regulatory ecosystem services.

(ii) The predefined keywords should exist as a whole at least in the title, keywords, or abstract section of the paper.

(iii) The paper should be published in a scientific peerreviewed journal between 2005 and the cutoff date on April 18 of 2019. This period of time was linked with the work of MA report, and the terms ecosystem and ecosystem services were consistently used.

(iv) The paper should be written in the English language. Next, the selected papers were then subjected to further analysis.

\section{Data collection}

Basic information was extracted from 46 articles that cover the types of ES studied and their indicators (like climate regulation and erosion control); methods of quantification/mapping, i.e., biophysical or economic terms; and the ecosystem types (forest ecosystem, watershed, agricultural land, and the like). The data were organized on the general characteristics of the articles and on the specific parameters used to value/quantify/map the ES. The general information of the articles includes the year of publication, analysis types (quantitative, qualitative, mapping, or mixed), types of study and scale, numbers of ES assessed, and country/region where the study was conducted, whereas the rest of the publication was used for generating existed knowledge and trends of research on the topic.

\section{Data analysis and presentation}

The data from the final list of selected articles were summarized to identify and qualitatively assess the 
Table 1 Searching outputs from ScienceDirect, Scopus, and Google Scholar database of time span 2005 to April of 2019

\begin{tabular}{lllll}
\hline & Searching terms & \multicolumn{2}{l}{ No. of research articles } \\
\cline { 3 - 4 } Main searching terms & ScienceDirect & Scopus & Google Scholar: Advanced search \\
\hline & $\begin{array}{l}\text { Regulating ecosystem services or regulating } \\
\text { services or regulatory ecosystem services or } \\
\text { regulatory services }\end{array}$ & 521 & 893 & $\begin{array}{l}75 \text { articles, books and book chapters, proceedings, } \\
\text { and theses by putting the searching terms in the } \\
\text { quotation. }\end{array}$ \\
& $\begin{array}{llll}\text { Climate regulation } \\
\text { Wabs-key }\end{array}$ & 282 & 231 & 198 \\
& Erosion regulation & 455 & 85 \\
& Disease regulation & 55 & 11 \\
& Pest regulation & 28 & 6 & \\
\hline
\end{tabular}

Both Scopus and ScienceDirect databases constitute more publications on climate and water regulation services, but ScienceDirect also had large publications on pollination services

current knowledge on RES, spatial scale and ecosystems, type of assessments used, and gaps observed. The systematic review also captures the state of the research for policy implication and implementation and the kinds of scientific research needed in the future from various disciplines that have interest and capability to conduct research.

\section{Results}

\section{Research trends in ecosystem service}

The literature search result depicts that recently, there were enormous scientific publications on the field of ES on diverse ecosystem types. Until the publication of articles on ES, for instance, Costanza et al. (1997) and Daily (1997), the concept and application of ES in the scientific sphere were limited (Weitzman 2019). Since 2010, the number of publications had increased exponentially though few publications on ES existed before 2010. This is a common trend in ES research, and the possible reason would be emerging of specific journals on ES in the mid-2000s and the existence of seminar and workshop at international level on ES (Costanza et al. 2017;
Liquete et al. 2013; Mengist and Soromessa 2019). Mainly after the publication of the MA report in 2005, the scientific community was inspired to conduct studies on the various benefits of ecosystems for human wellbeing. This indicates the existence of an academic interest in ES studies so as to inform policymakers to design strategies to use ecosystems sustainably. Relatively, the publication size on RES was not large, for example, publications indexed in the Scopus database that addressed RES were eight in 2005 and reached 100 in 2018 (Fig. 1).

\section{RES indicators and spatial distribution of the selected studies}

Compared to the total number of publications indexed in the Scopus database, only some of them contain the phrase "regulating ecosystem services"/"regulating services"/"regulatory ecosystem services" or "regulatory services," in their title or abstract and keywords. Beyond that, only a few of them focus on the quantification/ mapping/valuing of one or more RES indicators, and the majority of works were general assessments. Results were generally given as the absolute number from the

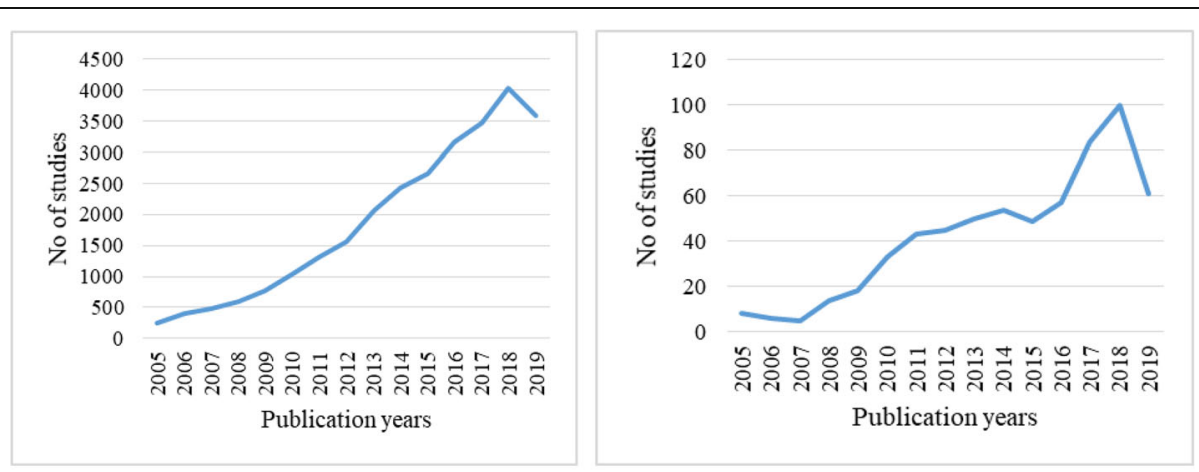

A) Publication trends on ES

B) Publication trends on regulatory ecosystem services

Fig. 1 The number of papers published annually from 2005 to April 2019. a Publication trends on ES. b Publication trends on regulatory ecosystem services 
selected case studies, followed by the percentage share of case studies in parentheses. From the 46 publications sourced for this meta-synthesis, 27 (58.7\%) discussed a single RES, eight (17.4\%) studied two RES, seven (15.2\%) discussed three RES, and four (8.7\%) papers included four RES. The majority of the publications merged different indicators of ES with other functional groups like provisioning, cultural, and supporting services.

Figure 2 describes the spatial distribution of regulating ecosystem service studies. The 46 studies were conducted in six continents: in Asia (12 studies), Europe (19 studies), Africa (9 studies), Australia (1 study), North America (4 studies), and South America (1 study). The study represented 26 countries except for the four studies that were conducted at the regional level in Europe that cover more than one country. The selected studies had covered nine, seven, five, and three countries from Europe, Africa, Asia, and America, respectively, and Australia had a single study. This diverse geographic focus and being conducted at various spatial scales suggest an understanding that RES is relevant for ecosystems and human health. The selected case studies covered small areas of the world and were not enough to cover the various indicators of RES. Even though small, the literature on RES has been growing steadily over the last few years. All the selected publications had got published since 2010, and the possible reason might be the subsequent publication of TEEB in 2010, the
IPEBS in 2012, and the existence of a seminar on ES at the international level.

There is a diversity of ES classification that causes difficulties and inconvenience in the comparison between different studies (Fletcher et al. 2011). Besides, there were difficulties to match the RES indicators used by some studies with the classification of MA (2005). However, this challenge was overcome, except for the uncategorized service, as follows. As shown in Table 2, ES such as "flood regulation," "bird predation of herbivorous insects," and "cyclone regulation" were grouped under natural hazard regulation. Also, "carbon storage," "carbon sequestration," "climate regulation," "micro-climate regulation," "temperature," "thermal comfort of inhabitants," and "urban heat islands" were categorized under climate regulation in this paper classification. The previous classification by Liquete et al. (2013) incorporates "weather regulation" as an independent of climate regulation considering their scale, processes, and beneficiaries.

\section{Current knowledge on regulating services}

The services mentioned by the selected 46 papers were grouped into those in which the services belong. Based on the indicators of RES, most of the literature addressed climate regulation services that had 25 cases followed by natural hazard regulation, water regulation, and erosion regulation by 12,10 , and 9 cases,

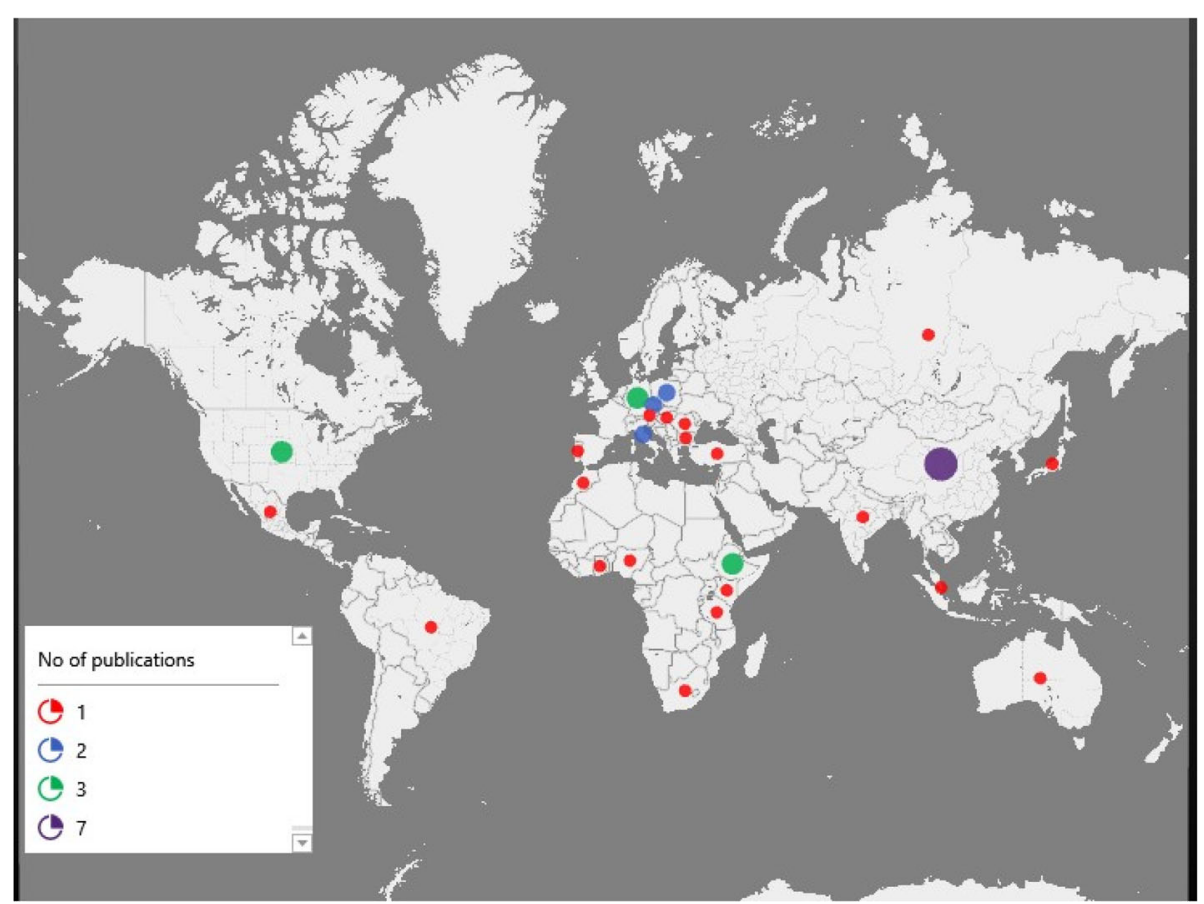

Fig. 2 The distribution of RES case studies globally based on study location ( $N=46$ studies which specified a geographic location). The publications on RES that were published from 2005 to 2019 demonstrate a broad spread across the globe, with a relatively notable concentration of studies in Europe and Africa 
Table 2 The correspondence of the classification of RES proposed in this paper with other previous research work classifications

\begin{tabular}{|c|c|c|c|}
\hline This paper & (MA 2005) & (Liquete et al. 2013) & (Beaumont et al. 2007) \\
\hline \multirow[t]{2}{*}{ Water quality and purification } & Water purification and waste treatment & Water purification & Bioremediation of waste \\
\hline & Nutrient cycling & & Nutrient cycling \\
\hline Air quality regulation & Air quality regulation & Air quality regulation & Gas and climate regulation \\
\hline Natural hazard regulation & Natural hazard regulation & Coastal protection & Disturbance prevention \\
\hline Water flow regulation & Water regulation & & \\
\hline Erosion regulation & Erosion regulation & & \\
\hline \multicolumn{4}{|l|}{ Soil/sediment retention } \\
\hline $\begin{array}{l}\text { Climate regulation, micro-climate, carbon storage, } \\
\text { and sequestration, urban heat islands }\end{array}$ & Climate regulation & Climate regulation & Gas and climate regulation \\
\hline Noise reduction & & Weather regulation & \\
\hline Nutrient cycling & Nutrient cycling & Ocean nourishment & Nutrient cycling \\
\hline Pollination & Pollination & Life cycle maintenance & Biological mediated habitat \\
\hline Pest regulation & Pest regulation & Biological regulation & N/A \\
\hline Disease regulation & Disease regulation & & \\
\hline
\end{tabular}

ES such as "carbon storage," "carbon sequestration," "climate regulation," "micro-climate regulation," "temperature," "thermal comfort of inhabitants," and "urban heat islands" in this paper has been grouped under climate regulation

respectively. However, none of the studies covers the pollination services of ecosystems (see Fig. 3). A study in the USA by Brainard et al. (2016) assessed the pest regulatory services, and Inkoom et al. (2018) studied pest and disease regulation services on a terrestrial landmass in Ghana. A study by Bicking et al. (2018) on a mapping of nutrient regulating ecosystem service by using the nutrient nitrogen is an example in Germany. The study used a local and regional scale study site to infer the conclusion on the spatial scale effect of nutrient RES. The study determined the existence of a regional differentiation on the supply and demands of nutrient regulation.
From the selected 46 number of literature, the total number of indicators of RES addressed was summed up 75. Multiple RES indicators were taken from a single study when they represent each indicator separately, and according to Brander et al. (2013), this is one of the peculiar characters which a meta-analysis should control. Except for a single study, the rest of the case studies were categorized into either of the indicators in RES. The uncategorized study was a study by Davies et al. (2017) in Britain on urban trees. It was a general study and tried to address and identify constraints and drivers to apply the ecosystem service approach to urban forest management by British local authorities. As a result, the

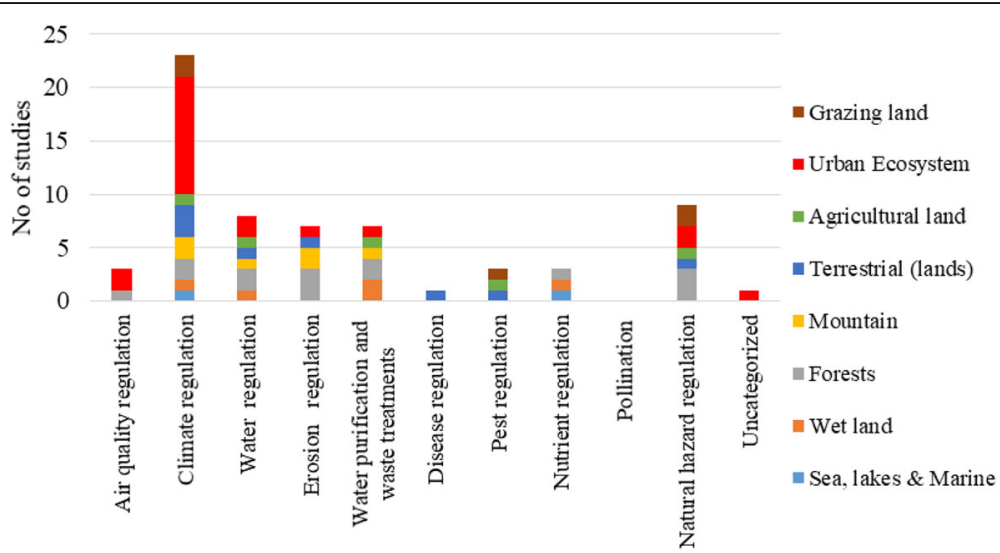

Fig. 3 The number of case studies and RES indicators based on MA 2005 classification. Based on indicators of RES, climate regulation and natural hazards were relatively well studied, whereas the pollination, pest, and disease regulation services were the least studied. Based on the studied ecosystems, urban and forest ecosystems had more case studies compared to sea/marine, wetlands, and grazing lands 
study did not address a single indicator from RES to derive a conclusion.

Based on the ecosystem type, the urban ecosystem had 20 number of case studies of which more than half cover climate regulatory services that include urban heat, temperature, microclimate, carbon storage, and sequestration. Climate regulation service was well studied in the urban ecosystem than any other. The next landscape type was the forest that had 15 case studies of which climate regulation and natural hazard regulation services were relatively well addressed (see Fig. 3 and Table 3). On the other hand, the less studied ecosystems were sea and marine ecosystems, grazing lands, and wetlands. Such ecosystem site needs scientific studies to evaluate/ quantify/map the various regulatory ecosystem services that the ecosystems have had to the well-being of human society. Thus, the result from different categories of RES is underpinning the existence of confusion between priority and sensitivity to human well-being.

The RES studies had various variables of interest (Fig. 4), and numerical crosses were made between the scale of the study site and the ecosystem. The classification of study size scale was done by modifying the Martínez-Harms and Balvanera (2012). It was concluded that 34 (73.9\%) of the papers were conducted at local (watershed, river catchment, cities) scale, eight (17.4\%) papers at a national level (covering the whole geographic area of a country), and four (8.7\%) papers at regional (studies covering the whole continent or more than one country administrative areas) scale. In addition, the total areal extent of the study used for the assessment of RES was a range from small size to a larger size ecosystem area in hectares. For instance, from the selected studies, which clearly defined the total study area covered by their work, the smallest size was 7.2 ha in Turkey at the urban garden site for the assessment of carbon storage and sequestration and runoff retention (Hepcan and Hepcan 2018), and the largest area coverage was 139 million hectares of lands in China to study water and climate regulation in alpine grassland ecosystem (Pan et al. 2014). This infers that most of regulatory ecosystem service indicators were studied at small-scale areas with the main aim of producing site-specific knowledge and information on the valuing and mapping of the ecosystem types.

During the review, the only continent that had studies covering the entire geographic space was Europe with three studies. The first study was on mapping the flood regulation services in Europe to provide spatial analysis on its demand and supply side by Stürck et al. (2014). The second was a study by Stürck et al. (2015) on regulating ecosystem services that consider the role of past and future land use change across time and space. They studied the effect of historic land use land cover change on the supply and demand of RES, except Croatia. The third was by Larondelle et al. (2014) on mapping the diversity of regulating ecosystem services in European cities. The study analyzed the provision of ecosystem services in 301 large urban zones from 27 European countries.

As shown in Fig. 5, in terms of year of publication, the selected literature includes publication which started in 2011, even if the search was between 2005 and April of 2019. There was no publication included in the final selected papers that cover the period from 2005 to 2010 . The smallest number of publications was recorded in 2011, 2012, and 2013, whereas the largest publication

Table 3 Overview of different RES indicators in urban and forest ecosystems studied by the selected papers

\begin{tabular}{|c|c|c|c|c|}
\hline Ecosystems & RES indicators & Scale & Purpose & Sources \\
\hline \multirow[t]{6}{*}{ Urban } & $\begin{array}{l}\text { Climate regulation } \\
\text { (carbon storage and } \\
\text { sequestration; urban } \\
\text { heat islands) }\end{array}$ & Local & $\begin{array}{l}\text { To generate site specific } \\
\text { knowledge }\end{array}$ & $\begin{array}{l}\text { (Almeida et al. 2018; Coskun Hepcan and } \\
\text { Hepcan 2018; Giedych and Maksymiuk 2017; } \\
\text { Kong et al. 2016; Marando et al. 2019; Richards } \\
\text { and Edwards 2017; Scholz et al. 2018) }\end{array}$ \\
\hline & & Regional & Policy implication & (Larondelle et al. 2014) \\
\hline & $\begin{array}{l}\text { Natural hazard (flood } \\
\text { and cyclone regulation) }\end{array}$ & Local & $\begin{array}{l}\text { To generate site-specific } \\
\text { knowledge }\end{array}$ & (Wang et al. 2019) \\
\hline & & & Methodological development & (Nedkov and Burkhard 2012) \\
\hline & & & For policy implication & (Davies et al. 2017) \\
\hline & $\begin{array}{l}\text { Air quality and water } \\
\text { regulation }\end{array}$ & Local & $\begin{array}{l}\text { To generate site-specific } \\
\text { knowledge }\end{array}$ & $\begin{array}{l}\text { (Almeida et al. 2018; Giedych and Maksymiuk 2017; } \\
\text { Manes et al. 2016; Wang et al. 2019) }\end{array}$ \\
\hline \multirow[t]{3}{*}{ Forest } & $\begin{array}{l}\text { Climate regulation } \\
\text { (carbon sequestration, } \\
\text { micro-climate } \\
\text { regulation) }\end{array}$ & $\begin{array}{l}\text { Local-national- } \\
\text { regional scales }\end{array}$ & $\begin{array}{l}\text { To generate site-specific } \\
\text { information and knowledge }\end{array}$ & (Alamgir et al. 2016; Ghazi et al. 2018; Stürck et al. 2015) \\
\hline & $\begin{array}{l}\text { Air quality and water } \\
\text { regulation }\end{array}$ & $\begin{array}{l}\text { Local to national } \\
\text { scale }\end{array}$ & $\begin{array}{l}\text { To generate site-specific } \\
\text { information and knowledge }\end{array}$ & $\begin{array}{l}\text { (Alamgir et al. 2016; Ghazi et al. 2018; LoTemplio et al. } \\
\text { 2017) }\end{array}$ \\
\hline & $\begin{array}{l}\text { Natural hazard (flood } \\
\text { and cyclone regulation) }\end{array}$ & At country level & $\begin{array}{l}\text { To generate site-specific } \\
\text { information and knowledge }\end{array}$ & (Alamgir et al. 2016; Oka et al. 2019) \\
\hline
\end{tabular}




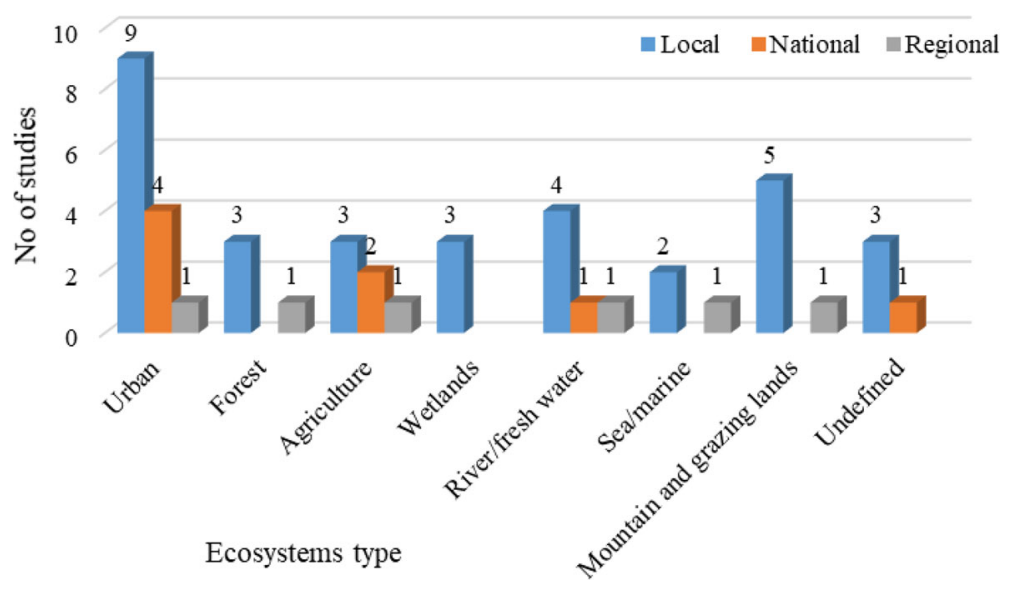

Fig. 4 The number of studies across scale levels and ecosystems

number was in 2016 and 2018. In sum, the number of the publication including the term regulating/regulatory ecosystem services in the title of the articles was insignificant.

\section{Regulatory ES: study approaches and methods}

Several distinct types of RES studies can be distinguished. It can be broadly categorized into RES assessments at specific sites using modeling and valuation, review and theoretical papers for conceptual development, and methodological papers for checking approaches, testing, and developing methods. RES studies involve various kinds of methods to quantify values and map the service. The common techniques employed by researchers were either biophysical or integrating biophysical and economic/monetary terms (Fig. 6). The biophysical method refers to the value of the ecosystem in tons per hectare estimation, monetary terms like financial benefits and/or costs per hectare and year estimation, and the rest used percentages, scoring, and for the socio-cultural value of ES to society. It was the most common (48\%) followed by research works that integrated both biophysical and economic/monetary terms (22\%), to quantify either singular or multiple ecosystem services.

In terms of data types, 22 studies (47.8\%) used mixed data of primary and secondary sources; thirteen studies (28.3\%) and eleven studies (23.9\%) used primary and secondary data types, respectively. Thus, less than $30 \%$ of the studies derived their results using primary data of field observations or actual measurements, whereas nearly one-fourth based their results on secondary data.

Figure 7 represents the category of the selected published articles based on the purposes of the research conducted. Most of the studies, which constitute 78.3\%, were for the generation of site-specific knowledge on various indicators of RES across different landscapes. However, few studies had a research purpose for

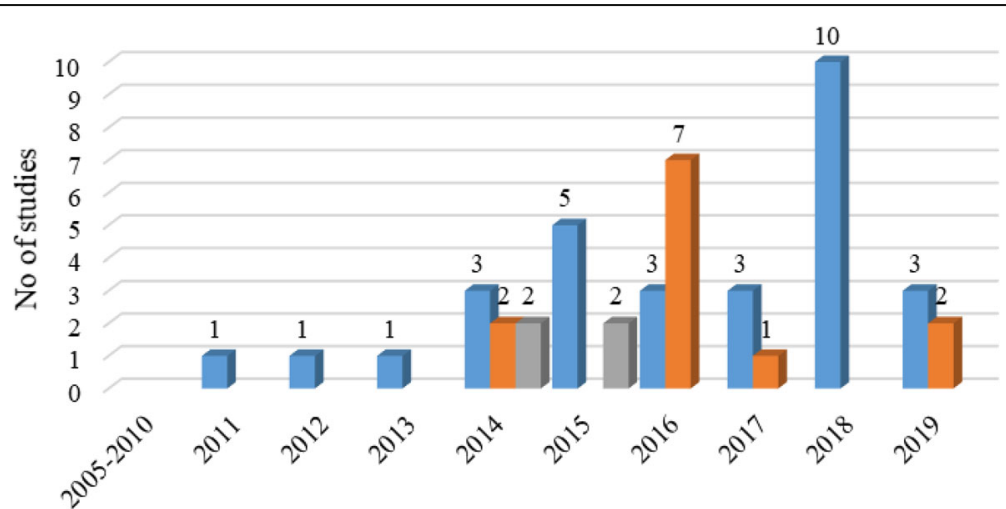

Year of publications

Local scale National scale $\quad$ Regional scale

Fig. 5 The number of studies of the selected literature based on study scale and year of publications 


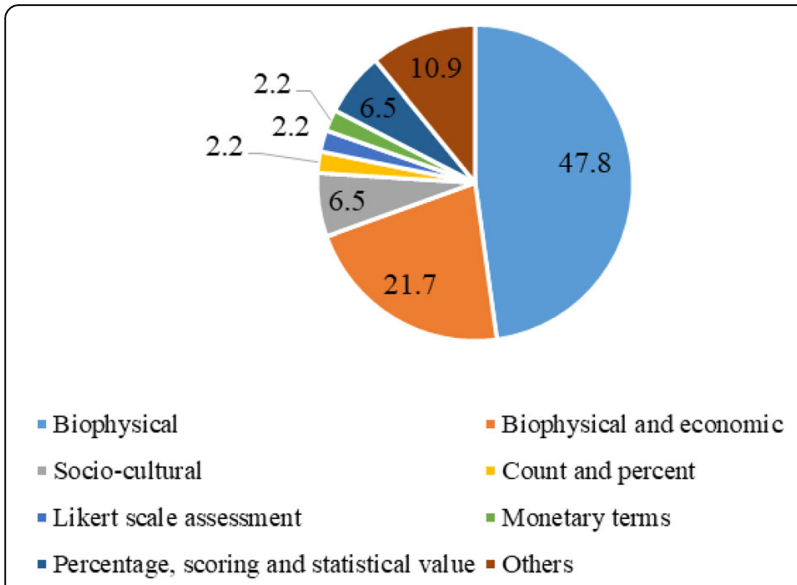

Fig. 6 Methods of assessments used by the selected publications

methodological assessment and development, mainstreaming ecosystem services with policy agenda, and recommending management options to maintain both the quality and quantity of the benefits of the given ecosystem service to human well-being.

\section{Gaps and difficulties observed in RES studies}

The majority of the selected studies, namely 28 papers (60.9\%), had not explicitly mentioned the difficulties and limitations in their study. However, they either recommend the need to conduct another study or their study is the first in its kind in the locality. This implies that the concept of ecosystem services research is recent and demands a lot of research work to make it rich in its methodology and models. Based on the challenges and limitation mentioned by the selected published articles, the existence of methodological uncertainties is mentioned by $17.4 \%$ ( 8 papers) which was followed by data and model limitations, which is present and discussed in $10.9 \%$ (5 papers) and $8.7 \%$ (4 papers) of the selected papers, respectively (Fig. 8). According to Grêt-Regamey et al. (2013), uncertainty in ES valuation and quantification has a significant impact on the amount of the predicted value. For instance, in a study in Landschaft Davos on carbon sequestration, uncertainties caused a change in its total value by $48 \%$ (Grêt-Regamey et al. 2013).

\section{Discussion}

\section{Spatial distribution and focus area of RES studies}

The study result revealed that research on RES has shown more concentration in Europe and Asia which together shared more than two-thirds from the total selected papers. In agreement with another review on ecosystem services, at individual country level, China had shared the largest number of publications and the result was in agreement with the study of Luederitz et al. (2015), but she ranked next to the USA in Seppelt et al. (2011) review work. The number might be larger than this if the review work covers publication from the Chinese language. Because China had a journal (Shengtai Xuebao/Acta Ecologica Sinica) that published a number of articles on urban ecosystem services (Luederitz et al. 2015). A meta-analysis and systematic review work that excluded publications of non-English language may miss important research findings.

Ecosystems provide multiple ES to human beings (Lee and Lautenbach 2016). Regardless of the reason behind the abundance of studies on urban and forest ES (Table 3), the result indicates that they play an important role in human safety and thus the best available methods attracted researchers. Besides, most of the case studies were conducted spatially at the local level. Similarly, Malinga et al. (2015) reported that $92 \%$ of the studies were conducted at a local scale, and the reason was the availability of secondary data at this scale. Based on RES indicators, climate regulation service was the most investigated topic in several publications. One of the reasons for the existence of large study output on climate regulation service was the establishments

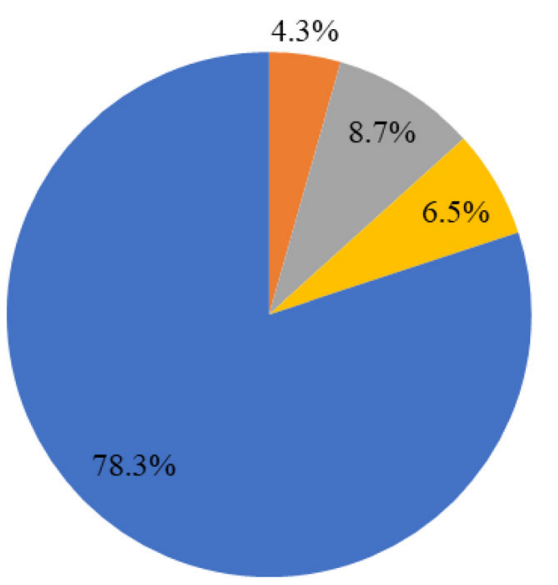

Management option

Methodological assessment

- Policy implications

$\square$ Site-specific knowledge

Fig. 7 Main purposes of the selected published articles 


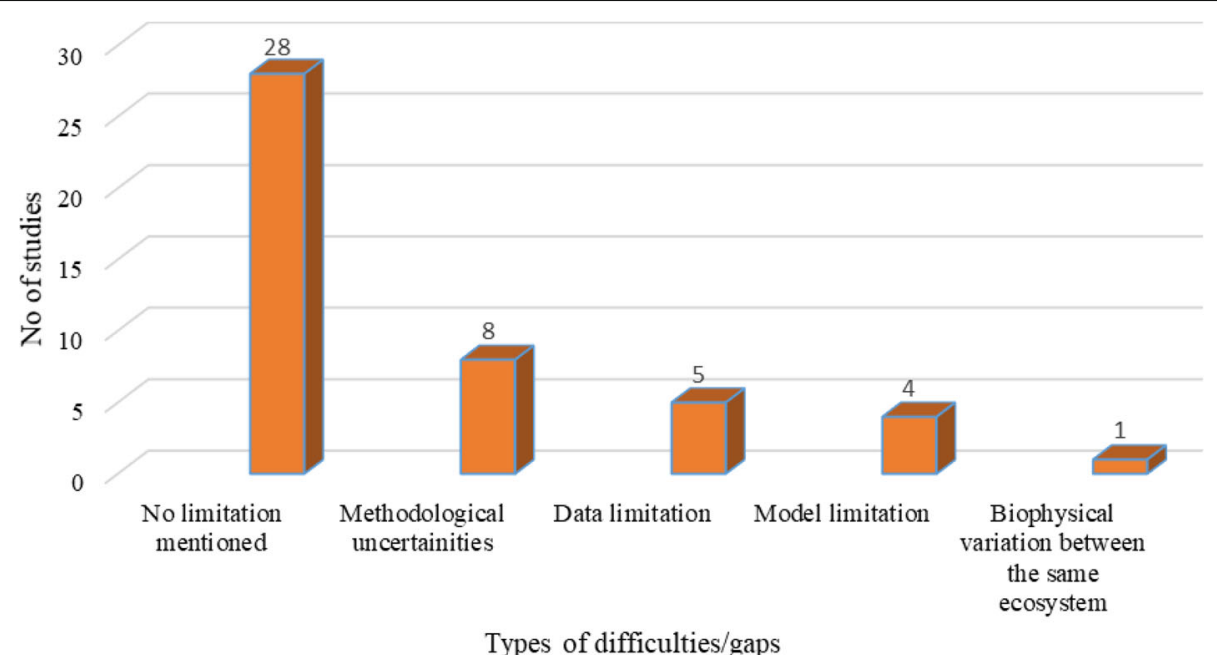

Fig. 8 The most common difficulties mentioned by the selected studies

of "The Intergovernmental Panel for Climate Change" and "reducing emissions from deforestation and forest degradation in developing countries, and the role of conservation, sustainable management of forests, and enhancement of forest carbon stocks in developing countries" (Goslee et al. 2016). These consequently increase the information demands of most governments and many other international organizations (Egoh et al. 2012). However, the study untouched the effect of the trade-offs of climatic extremes such as severe drought and global warming impacts that could negatively affect ecosystem functioning and stability. Other ecosystems like wetlands, sea/marine, and grazing land ecosystems had the least attention in the research community though they have had a significant contribution to human well-being. This created unbalanced research works and outputs on the different types of ecosystems and indicators of RES. In addition, the study found out the presence of less care for documenting valuable information in the articles like the geographical extent of the study site for instance (Krkoška Lorencová et al. 2016; Li et al. 2018; Walz et al. 2019) and lack of stating explicitly the difficulties that impact the study findings.

The dominance of site-specific ecosystem assessment was observed. This was mainly applied to evaluate/quantify/map the specific ecosystem types using monetary and/ or biophysical terms. On the other hand, the number of publications focusing on policy implication and suggesting methodological options was too small. This might be linked with the development level of the concept and the methodological advancement to measure the ecosystem services to persuade policymaker institutions.

\section{Research gaps and future direction}

This review has illustrated the view on RES studies, but more than looking for gaps in RES research, our motive was to find those habitats and indicators for which research should be prioritized. The existing research work thus considered spatial extents ranging from local case studies to regional and global assessments. Results show that research was compelled by divers' motives like generating sitespecific knowledge, methodological development, policy implication, and management options (Fig. 7).

Though the difficulties mentioned in the reviewed papers, which are displayed in Fig. 8, were mainly focused on uncertainties from methodological and data types, we identified additional gaps in RES studies. These gaps may inhibit future progress in RES studies and slowly mainstreaming them into the decision-making process. The identified gaps were grouped into five basic research gaps. First, the literature misses a fair representation of studies from each indicator of RES and ecosystems. The existed studies concentrated on climate regulation, hazard regulation, water, and erosion regulation. There was no sufficient outlook on pollination, pest and disease, air quality regulation, and nutrient regulation services. Mengist and Soromessa (2019) have noticed in their metaanalysis study that the pollination, pest, and human disease regulation services were the least addressed and received less attention from the scientific community. Among other things, the most common factors would be related to lack of data, challenges in estimating their value, and lack of well-designed methods. In terms of ecosystems, there are no adequate studies on wetlands, grazing lands, and sea/marine ecosystems. These ecosystems need critical studies using biophysical, monetary/ socio-economic, and socio-cultural data. Comparatively, an urban ecosystem is widely investigated in scientific works from all indicators except in terms of pest and disease and pollination services. Though the topic is novel, it is unsurprising that most studies examine the 
general view on the value of the RES. There is a lack of an adequate number of studies that able to assess the various biomes of its regulatory services and/or challenges that affect those potentials.

Second, most studies were site-specific and conducted by multi-disciplinary teams but lack forwarding strategies to link ES into the decision-making process. According to Droste et al. (2018) and Malinauskaite et al. (2019), ecosystem service research needs multidisciplinary collaboration as well as the inclusion of local perspectives by involving local stakeholders. Most of the papers in this review work had a transdisciplinary background and are important to mainstreaming the concept with government policy, though the actual effort was weak. The same concept was mentioned by Weyland et al. (2019); mainstreaming ecosystem service assessment into policymaking is helpful at the initial stage of the ecosystem service management phase. Besides, the notion of ES is increasingly used for making a decision on natural resource management (Grêt-Regamey et al. 2013), and in the long run, the use of ES concept can help to develop policies to bring sustainability on the functioning of ecosystems and its benefits into society (Balvanera et al. 2012). Thus, most of the selected RES papers had predominantly discussed the conceptual and theoretical aspects, with only a few exceptions of case studies for instance (Ifatimehin 2014; Missall et al. 2015; Oka et al. 2019) those which address the interaction between human well-being and ecosystem services.

At least the following two possible reasons can be outlined to explain for lack of mainstreaming outputs of RES studies into policymaking agenda: (i) it demands the studies to have detailed and accurate information across various spatio-temporal scale (Caro et al. 2020; Englund et al. 2017), and (ii) it needs sound result on the socioecological interrelationship between society and ecosystems, the ES society gain from the natural habitats, and human influence on the specified habitats (Lautenbach et al. 2019).

Third, there is a dearth of uniform methodology and inconsistency in ecosystem service classification. Both biophysical and/or monetary terms can be used in similar indicators and ecosystems, but the challenge was inconsistency in ES classification. This may confirm that gaps remain in the ES classification. Similar to Nemec and Raudsepp-Hearne (2013) and Englund et al. (2017), we find the existence of methodological and ES classification diversity on ES research. This may create difficulties to integrate ES assessment results for meta-analysis studies-an issue which is already discussed in CICES itself by Haines-Young and Potschin (2011) and recently by Englund et al. (2017). In this context, providing simple and easy-to-use methods, models, tools, and ES classification is fundamental to guarantee a successful integration of knowledge on regulatory services. On the other way, the existence of diverse ways of ES classification confirms that there are many useful ways to classify ecosystem goods and services. These pluralisms of ES classification may be helpful for studies to address different goals (Englund et al. 2017).

This is perhaps similar to the findings from Seppelt et al. (2011) that aimed to quantitatively review of ecosystem service studies and the existence of inconsistent ES classification impacting to categorize in any of the RES indicators. A similar conclusion was formed by Fisher et al. (2009) that inconsistency of ES classification can cause challenges for making meaningful research results and difficulties to make comparisons and integration of study output with other data (Englund et al. 2017). According to Villamagna et al. (2013), therefore, to improve RES assessments, developing methodology is a prerequisite. In the real term, there is no one-size-fitsall approach to assess ecosystem benefits. It is important to be aware of the limitation of existing ES classification. Thus, choosing the most suitable ES classification that considers the purpose of studies is mandatory (Heink et al. 2016; La Notte et al. 2017). The type and size of benefits are related to the ecosystems. For instance, a heterogeneous landscape can provide many ES. To reduce the challenge, the application of appropriate methods that examine the data availability, time frame, competence, and others to quantify the capacity, demand, and flow services is essential (Englund et al. 2017; Nemec and Raudsepp-Hearne 2013).

The fourth challenge is the lack of nearly balanced monetary value estimation per hectare per annum for nearly similar ecosystems. A meta-analysis on the forest ecosystem services valuation methods by Mengist and Soromessa (2019) also concluded that methodological inconsistency on monetary estimation exists for similar ecosystems across the globe. There was also a challenge related to the existence of a small number of case studies on similar ecosystems and indicators of RES. This can be a research challenge in the future to make systematic analysis and comparison across site and scale, as also emphasized by Malinga et al. (2015). As a solution, Costanza et al. (2017) forwarded the scientific community to develop a methodology that helps to map, model, value, and manage ecosystem services and to effectively address the final output to the end-users. Finally, numerous studies found in this review had a small area coverage in hectares. However, their methods were poorly described, lack a detailed description of the data sources, and have no justification for the use of generic data and models at a small-scale level of studies. This might be due to the high cost of resources and time for the primary data collection, as also noticed by Malinga et al. (2015) and Nemec and Raudsepp-Hearne (2013). As a 
result, the researchers have more relied on secondary data sources for ES estimation and assessment. This was supported by the study of Martínez-Harms and Balvanera (2012) that one of the most common approaches in RES study was the application of secondary data to model ecosystem services.

Therefore, there should be high research outputs with regard to RES across different ecosystems using regulatory ES indicators, because it is not yet possible to fully account the role and benefits of RES to human safety and for other ES provision. Also, there is no adequate size of studies to mainstreaming RES into the policymaking agenda. In parallel, Sutherland et al. (2018) suggest improving ES assessment frameworks "by including indicators of regulating ES that differentiate between the capacity to provide a regulating ES, the demand for the same, and the actual service that is conveyed."

\section{Comparison to other ecosystem service review work}

The research gaps mentioned in this paper coincided with other review work on ecosystem services. One of the main challenges was the inconsistency in methodology and terminology used by the studies. Englund et al. (2017) reviewed "How to analyze ecosystem services in landscapes" and claimed that the existence of inconsistency in the use of terminology affects the choice of methods used to value the services. Similarly, Costanza et al. (2017) and Mengist et al. (2019a) highlighted that ES research had inconsistent approaches to model, assess, and value ES. There was variation in the priority given to RES indicators and ecosystem types which was also reported by Balvanera et al. (2012) on ecosystem service studies in Latin America. They mentioned that the current ES research work focuses on those having impacts at a global level like carbon and a regional scale (water resources). On the contrary, other ES like disease regulation, coastal protection, pollination, and floods that have local-level importance had got less priority by the scientific communities.

The interdisciplinary nature of ecosystem service work was observed in this systematic review work. The result was also supported by the findings of Malinga et al. (2015) and Abson et al. (2014). This was also pinpointed by Droste et al. (2018) that interdisciplinary research work and multiple perspectives and types of ES values were observed in ES researches. Another common concern, which coincides with the observation of this study, was the lack of forwarding clear strategies in the selected papers to integrate ecosystem services into a national policy of resource management and mainstreaming to other development agenda (Malinauskaite et al. 2019; Sutherland et al. 2018). However, mainstreaming ES to policymaking and development agenda needs efficient and explicit information both on the status and trends of the ecosystem and its associated benefits (Maes et al. 2012).

\section{Limitations of the review}

This study attempts to assess the general trends, the types of RES indicators and ecosystems, and the gaps observed in RES studies that were conducted from 2005 to April of 2019 at the global level. The assessment tried to indicate the current state of knowledge in RES and the indicators versus ecosystems that had more focus and the least attention from the scientific community. It is not, however, this systematic review free from limitations. Firstly, the assessment ignores publications that have a concern on RES without including the term regulating ecosystem services in the title of the article. The second limitation was linked to the databases used to search related literature on the issue. Other data sources like the Web of Knowledge were inaccessible to search the archives to broaden the possibility of including more number of related publications. The third limitation was the review process considered only peer-reviewed published articles on the English language. However, research on ecosystem services is rapidly changing and research publications are being published in a significant amount using other languages like Chinese, Spanish, and others. Other publications like proceedings, grey literature and policy documents, or publications written both in English and other languages were excluded. Therefore, the limitation was unavoidable and led to overlook some relevant publications.

\section{Conclusion}

Despite broad recognition of the benefits of ES, several knowledge gaps can be identified on the basis of the overview given in this article. Among them, existing studies on valuing and assessing RES fall short of the need to mainstreaming into decision-making and integrating into national-level environmental resource management strategies. This was due to the fact that valuing RES is not easy compared to other ES that has a direct link with human well-being. There was also the use of multiple ES classifications and naming that makes comparison and meta-analysis of studies and assessments more difficult. As per a prerequisite, designing a common ground that permits comparison between RES assessments from different study sites has become more urgent.

In the last decade, ecosystem service studies increased steadily, but relatively no significant number of studies were found from regulatory services, whereas the existing studies were concentrated on urban and forest ecosystems as they have more developed methods and link with human safety. Thus, the existing knowledge generated on the importance of RES is still limited and more 
research is needed to elucidate its synergy and tradeoff relation across space and time with other ES and human health.

We, therefore, propose that future research works should be painstakingly aiming to cover the RES that has local scale impacts such as pollination, pest regulation, disease regulation, and air quality regulating services. Besides, future studies should give priority for methodological development and proposing management options for improving the RES of ecosystems. Finally, most of the studies concentrated on secondary data and application of modeling to develop conceptual ideas even at local scale studies. Rather, scholars, therefore, are encouraged to integrate primary data for scrutinizing the link between human safety and RES.

\section{Abbreviations}

ES: Ecosystem service; MA: Millennium ecosystem assessment; RES: Regulating ecosystem services; SALSA: Search, appraisal, synthesis, analysis; TEEB: The economics of ecosystems and biodiversity

\section{Acknowledgements}

We thank the two anonymous reviewers for their suggestions and useful comments. We wish to thank both Addis Ababa University and DebreBerhan University for the support of this initiative.

\section{Authors' contributions}

MW had the initial idea and collected the related materials. ST and LG edited the manuscript and improved the language. All authors read and approved the final manuscript.

\section{Funding}

This research received no external funding

\section{Availability of data and materials}

Not applicable.

\section{Ethics approval and consent to participate}

Not applicable.

\section{Consent for publication}

Not applicable.

\section{Competing interests}

The authors declare that they have no competing interests.

Received: 22 April 2020 Accepted: 25 June 2020

Published online: 23 July 2020

\section{References}

Abson DJ, von Wehrden H, Baumgärtner S et al (2014) Ecosystem services as a boundary object for sustainability. Ecol Econ 103:29-37

Alamgir M, Pert PL, Turton SM (2014) A review of ecosystem services research in Australia reveals a gap in integrating climate change and impacts on ecosystem services. Int J Biodivers Sci Ecosyst Serv Manag 10(2):112-127

Alamgir M, Turton SM, Macgregor CJ, Pert PL (2016) Assessing regulating and provisioning ecosystem services in a contrasting tropical forest landscape. Ecol Indic 64:319-334

Almeida CMVB, Mariano MV, Agostinho F et al (2018) Comparing costs and supply of supporting and regulating services provided by urban parks at different spatial scales. Ecosyst Serv 30:236-247

Balvanera P, Uriarte M, Almeida-Leñero L et al (2012) Ecosystem services research in Latin America: the state of the art. Ecosyst Serv 2:56-70

Beaumont NJ, MC Austen, JP Atkins, D Burdon, S Degraer, TP Dentinho, S Derous, P Holm, T Horton, E van lerland, AH Marboe, DJ Starkey, M Townsend, and T Zarzycki (2007) "Identification, Definition and Quantification of Goods and
Services Provided by Marine Biodiversity. Implications for the Ecosystem Approach". Marine Pollution Bulletin 54(3):253-65.

Bicking S, Burkhard B, Kruse M, Müller F (2018) Mapping of nutrient regulating ecosystem service supply and demand on different scales in SchleswigHolstein, Germany. One Ecosystem 3:e22509

Boyd J, Banzhaf S (2007) What are ecosystem services? The need for standardized environmental accounting units. Ecol Econ 63:616-626

Braat LC, de Groot R (2012) The ecosystem services agenda: bridging the worlds of natural science and economics, conservation and development, and public and private policy. Ecosyst Serv 1:4-15

Brainard DC, Bryant A, Noyes DC, Haramoto ER, Szendrei Z (2016) Evaluating pest-regulating services under conservation agriculture: a case study in snap beans. Agric Ecosyst Environ 235:142-154

Brander L, Brouwer R, Wagtendonk AJ (2013) Economic valuation of regulating services provided by wetlands in agricultural landscapes: a meta-analysis. Ecol Eng 56:89-96

Burkhard B, Kroll F, Nedkov S, Müller F (2012) Mapping ecosystem service supply, demand and budgets. Ecol Indic 21:17-29

Caro C, Cunha PP, Marques J, Teixeira Z (2020) Identifying ecosystem services research hotspots to illustrate the importance of site-specific research: an Atlantic coastal region case study. Environ Sustain Indic 6:100031

Hepcan CC, Hepcan S (2018) Assessing regulating ecosystem services provided by the Ege University Rectorship Garden. Urban For Urban Green 34:10-16

Costanza R, d'Arge R, De Groot R et al (1997) The value of the world's ecosystem services and natural capital. Nature 387:253-260

Costanza R, de Groot R, Braat L et al (2017) Twenty years of ecosystem services: how far have we come and how far do we still need to go? Ecosyst Serv 28 : $1-16$

Daily GC (1997) Nature's services: societal dependence on natural ecosystems. Island Press, Washington, DC

Davies HJ, Doick KJ, Hudson MD, Schreckenberg K (2017) Challenges for tree officers to enhance the provision of regulating ecosystem services from urban forests. Environ Res 156:97-107

Deal RL, Cochran B, LaRocco G (2012) Bundling of ecosystem services to increase forestland value and enhance sustainable forest management. Forest Policy Econ 17:69-76

Droste N, D'Amato D, Goddard JJ (2018) Where communities intermingle, diversity grows - the evolution of topics in ecosystem service research. PLoS ONE 13(9):e0204749

Egoh B, Drakou E, Dunbar M, Maes J, Willemen L (2012) Indicators for mapping ecosystem services: a review JRC scientific and policy reports. Luxembourg 10:41823

Egoh B, Rouget M, Reyers B et al (2007) Integrating ecosystem services into conservation assessments: a review. Ecol Econ 63(4):714-721

Englund O, Berndes G, Cederberg C (2017) How to analyse ecosystem services in landscapes - a systematic review. Ecol Indic 73:492-504

Fagerholm N, Torralba M, Burgess PJ, Plieninger TA (2016) A systematic map of ecosystem services assessments around European agroforestry. Ecol Indic 62: 47-65

Fisher B, Turner RK, Morling P (2009) Defining and classifying ecosystem services for decision making. Ecol Econ 68:643-653

Fletcher S, Saunders J, Herbert R (2011) A review of the ecosystem services provided by broad-scale marine habitats in England's MPA network. J Coast Res:378-383

Ghazi H, Messouli M, Yacoubi Khebiza M, Egoh BN (2018) Mapping regulating services in Marrakesh Safi region - Morocco. J Arid Environ 159:54-65

Giedych R, Maksymiuk G (2017) Specific features of parks and their impact on regulation and cultural ecosystem services provision in Warsaw, Poland. Sustainability 9(5):792

Goslee K, Walker SM, Grais A, Murray L, Casarim F, Brown S (2016) Module C-CS: calculations for estimating carbon stocks

Grant MJ, Booth A (2009) A typology of reviews: an analysis of 14 review types and associated methodologies. Health Inf Libr J 26(2):91-108

Grêt-Regamey A, Brunner SH, Altwegg J, Bebi P (2013) Facing uncertainty in ecosystem services-based resource management. J Environ Manag 127:S145S154

Haines-Young R, Potschin M (2011) Common international classification of ecosystem services (CICES): 2011 Update. Report to the European Environmental Agency, Nottingham

Heink U, Hauck J, Jax K, Sukopp U (2016) Requirements for the selection of ecosystem service indicators-the case of MAES indicators. Ecol Indic 61:18-26 
Howe C, Suich H, Vira B, Mace GM (2014) Creating win-wins from trade-offs? Ecosystem services for human well-being: a meta-analysis of ecosystem service trade-offs and synergies in the real world. Glob Environ Chang 28: 263-275

Ifatimehin O (2014) Ecosystem Regulatory services and human comfort in an outdoor environment of Lokoja, Nigeria. Br J Appl Sci Technol 4(18):2576-2589

Inkoom JN, Frank S, Greve K, Furst C (2018) A framework to assess landscape structural capacity to provide regulating ecosystem services in West Africa. J Environ Manag 209:393-408

Kandziora M, Burkhard B, Müller F (2013) Interactions of ecosystem properties, ecosystem integrity and ecosystem service indicators - a theoretical matrix exercise. Ecol Indic 28:54-78

Keeler BL, Polasky S, Brauman KA et al (2012) Linking water quality and wellbeing for improved assessment and valuation of ecosystem services. Proc Natl Acad Sci 109(45):18619-18624

Kong F, Sun C, Liu F et al (2016) Energy saving potential of fragmented green spaces due to their temperature regulating ecosystem services in the summer. Appl Energy 183:1428-1440

Krkoška Lorencová E, Harmáčková ZV, Landová L, Pártl A, Vačkář D (2016) Assessing impact of land use and climate change on regulating ecosystem services in the Czech Republic. Ecosyst Health Sustain 2(3):e01210

La Notte A, D'Amato D, Mäkinen $\mathrm{H}$ et al (2017) Ecosystem services classification: a systems ecology perspective of the cascade framework. Ecol Indic 74:392-402

Larondelle N, Haase D, Kabisch N (2014) Mapping the diversity of regulating ecosystem services in European cities. Glob Environ Chang 26:119-129

Laurans Y, Rankovic A, Billé R, Pirard R, Mermet L (2013) Use of ecosystem services economic valuation for decision making: questioning a literature blindspot. J Environ Manag 119:208-219

Lautenbach S, Mupepele A-C, Dormann CF et al (2019) Blind spots in ecosystem services research and challenges for implementation. Reg Environ Chang:1-22

Lee H, Lautenbach S (2016) A quantitative review of relationships between ecosystem services. Ecol Indic 66:340-351

Li R, Zheng H, Lv S, Liao W, Lu F (2018) Development and evaluation of a new index to assess hydrologic regulating service at sub-watershed scale. Ecol Indic 86:9-17

Liquete C, Piroddi C, Drakou EG et al (2013) Current status and future prospects for the assessment of marine and coastal ecosystem services: a systematic review. PLoS One 8(7):e67737

LoTemplio S, Reynolds TW, Wassie Eshete A, Abrahams M, Bruesewitz D, Wall JA (2017) Ethiopian Orthodox church forests provide regulating and habitat services: evidence from stream sediment and aquatic insect analyses. Afr J Ecol 55(2):247-251

Luederitz C, Brink E, Gralla F et al (2015) A review of urban ecosystem services: six key challenges for future research. Ecosyst Serv 14:98-112

MA (2005) Ecosystems and human well-being: synthesis. Island Press, Washington, DC

Maes J, Egoh B, Willemen L et al (2012) Mapping ecosystem services for policy support and decision making in the European Union. Ecosyst Serv 1:31-39

Malinauskaite L, Cook D, Davíðosdóttir B, Ögmundardóttir H, Roman J (2019) Ecosystem services in the Arctic: a thematic review. Ecosyst Serv 36:100898

Malinga R, Gordon LJ, Jewitt G, Lindborg R (2015) Mapping ecosystem services across scales and continents - a review. Ecosyst Serv 13:57-63

Manes F, Marando F, Capotorti G et al (2016) Regulating ecosystem services of forests in ten Italian metropolitan cities: air quality improvement by $\mathrm{PM}_{10}$ and $\mathrm{O}_{3}$ removal. Ecol Indic 67:425-440

Marando F, Salvatori E, Sebastiani A, Fusaro L, Manes F (2019) Regulating ecosystem services and green infrastructure: assessment of urban heat island effect mitigation in the municipality of Rome, Italy. Ecol Model 392:92-102

Martínez-Harms MJ, Balvanera P (2012) Methods for mapping ecosystem service supply: a review. Int J Biodivers Sci Ecosyst Serv Manag 8(1-2):17-25

McDonough K, Hutchinson S, Moore T, Hutchinson J (2017) Analysis of publication trends in ecosystem services research. Ecosyst Serv 25:82-88

Mengist W, Soromessa T (2019) Assessment of forest ecosystem service research trends and methodological approaches at global level: a meta-analysis. Environ Syst Res 8(1):22

Mengist W, Soromessa T, Legese G (2019a) Ecosystem services research in mountainous regions: a systematic literature review on current knowledge and research gaps. Sci Total Environ 702:134581

Mengist W, Soromessa T, Legese G (2019b) Method for conducting systematic literature review and meta-analysis for environmental science research. MethodsX:100777
Milcu A, Hanspach J, Abson D, Fischer J (2013) Cultural ecosystem services: a literature review and prospects for future research. Ecol Soc 18(3):UNSP 44

Missall S, Welp M, Thevs N, Abliz A, Halik Ü (2015) Establishment and maintenance of regulating ecosystem services in a dryland area of central Asia, illustrated using the Kökyar Protection Forest, Aksu, NW China, as an example. Earth System Dynamics 6(1):359-373

Moher D, Liberati A, Tetzlaff J, Altman DG (2010) Preferred reporting items for systematic reviews and meta-analyses: the PRISMA statement. Int J Surg 8(5):336-341

Nedkov, Stoyan and Benjamin Burkhard (2012) "Flood Regulating Ecosystem Services - Mapping Supply and Demand, in the Etropole Municipality, Bulgaria". Ecological Indicators 21:67-79.

Nemec KT, Raudsepp-Hearne C (2013) The use of geographic information systems to map and assess ecosystem services. Biodivers Conserv 22(1):1-15

Oka C, Aiba M, Nakashizuka T (2019) Phylogenetic clustering in beneficial attributes of tree species directly linked to provisioning, regulating and cultural ecosystem services. Ecol Indic 96:477-495

Pan Y, Wu J, Xu Z (2014) Analysis of the tradeoffs between provisioning and regulating services from the perspective of varied share of net primary production in an alpine grassland ecosystem. Ecol Complex 17:79-86

Perevochtchikova M, Flores JÁH, Marín W, Flores AL, Bueno AR, Negrete IAR (2019) Systematic review of integrated studies on functional and thematic ecosystem services in Latin America, 1992-2017. Ecosyst Serv 36:100900

Richards DR, Edwards PJ (2017) Quantifying street tree regulating ecosystem services using Google Street View. Ecol Indic 77:31-40

Scholz T, Hof A, Schmitt T (2018) Cooling effects and regulating ecosystem services provided by urban trees - novel analysis approaches using urban tree cadastre data. Sustainability 10(3):712

Seppelt R, Dormann CF, Eppink FV, Lautenbach S, Schmidt S (2011) A quantitative review of ecosystem service studies: approaches, shortcomings and the road ahead. J Appl Ecol 48(3):630-636

Smith P, Ashmore MR, Black HI et al (2013) The role of ecosystems and their management in regulating climate, and soil, water and air quality. J Appl Ecol 50(4):812-829

Stürck J, Poortinga A, Verburg PH (2014) Mapping ecosystem services: the supply and demand of flood regulation services in Europe. Ecol Indic 38:198-211

Stürck J, Schulp CJE, Verburg PH (2015) Spatio-temporal dynamics of regulating ecosystem services in Europe - the role of past and future land use change. Appl Geogr 63:121-135

Sutherland IJ, Villamagna AM, Dallaire CO et al (2018) Undervalued and under pressure: a plea for greater attention toward regulating ecosystem services. Ecol Indic 94:23-32

Talbot CJ, Bennett EM, Cassell K et al (2018) The impact of flooding on aquatic ecosystem services. Biogeochemistry 141(3):439-461

Tancoigne E, Barbier M, Cointet J-P, Richard G (2014) The place of agricultural sciences in the literature on ecosystem services. Ecosyst Serv 10:35-48

Viglizzo EF, Jobbágy E, Ricard MF, Paruelo JM (2016) Partition of some key regulating services in terrestrial ecosystems: meta-analysis and review. Sc Total Environ 562:47-60

Villamagna AM, Angermeier PL, Bennett EM (2013) Capacity, pressure, demand, and flow: a conceptual framework for analyzing ecosystem service provision and delivery. Ecol Complex 15:114-121

Vo QT, Kuenzer C, Vo QM, Moder F, Oppelt N (2012) Review of valuation methods for mangrove ecosystem services. Ecol Indic 23:431-446

Walz U, Richter B, Grunewald K (2019) Indicators on the ecosystem service "regulation service of floodplains". Ecol Indic 102:547-556

Wang J, Chen S, Wang M (2019) How do spatial patterns impact regulation of water-related ecosystem services? Insights from a new town development in the Yangtze River Delta, China. Sustainability 11(7):2010

Wangai PW, Burkhard B, Müller F (2016) A review of studies on ecosystem services in Africa. Int J Sustain Built Environ 5(2):225-245

Watson R, Albon S, Aspinall R et al (2011) UK National Ecosystem Assessment: understanding nature's value to society. Synthesis of key findings. (eprints. lancs.ac.uk)

Weitzman J (2019) Applying the ecosystem services concept to aquaculture: a review of approaches, definitions, and uses. Ecosyst Serv 35:194-206

Weyland F, Mastrangelo ME, Auer AD et al (2019) Ecosystem services approach in Latin America: from theoretical promises to real applications. Ecosyst Serv 35:280-293

\section{Publisher's Note}

Springer Nature remains neutral with regard to jurisdictional claims in published maps and institutional affiliations. 